\title{
Regulation of Hemostasis by the Sympathetic Nervous System: Any Contribution to Coronary Artery Disease?
}

\author{
Daniel Preckel $^{a}$ Roland von Känel ${ }^{a, b}$ \\ a Institute for Behavioral Sciences, Swiss Federal Institute of Technology, Zurich, \\ bDepartment of General Internal Medicine, University Hospital Bern, Bern, Switzerland
}

\section{Key Words}

Hemostasis · Sympathetic nervous system • Adrenergic activation $\cdot$ Stress $\cdot$ Physical exercise

\begin{abstract}
Within the last two decades, hemostasis factors have emerged as 'new' risk factors for coronary artery disease. Historical studies on the physiology of the sympathetic nervous system (SNS) attributed accelerated blood clotting to the components of the fight-flight response. Although this has not been demonstrated, exaggerated clotting related to SNS hyperactivity might confer an increased arterial thrombotic risk. This review outlines the effects of sympathetic activation as mimicked by adrenergic infusions and as elicited by mental stress and physical exercise, and the molecular mechanisms involved. A selective review of the pertinent literature was undertaken. Sympathetic activation provokes a simultaneous increase in molecules of both the coagulation and fibrinolysis pathways within minutes, resulting in net hypercoagulability as a part of normal human physiology. Catecholamines and adrenergic receptors interact to mediate hemostatic changes. Exaggerated procoagulant changes in individuals with a preexistent atherosclerotic disease, in those experiencing ongoing stressful life circumstances and in the physically un-
\end{abstract}

trained might confer a thrombotic threat with sympathetic activation. Initial evidence suggests that nonselective $\beta$-adrenergic blockade may attenuate clotting acceleration upon SNS activation. Prospective studies are needed to demonstrate whether exaggerated clotting as elicited by the SNS is associated with an increased risk of cardiovascular morbidity and mortality. If confirmed, intervention studies targeted at reducing this risk, for example with drugs, psychotherapy (including stress management) and regular physical exercise, would be warranted.

Copyright $@ 2004$ S. Karger AG, Basel

\section{Introduction}

The subject of the regulation of various bodily processes by the sympathetic nervous system (SNS) is allotted considerable space in most textbooks of physiology. Oddly enough, although hastened blood coagulation was described as part of the fight-flight response almost one century ago [1], the effects of sympathetic activation on hemostasis have gained little attention in textbooks. Now that hemostatic factors have emerged as 'new' risk factors for atherosclerotic diseases [2], procoagulant changes related to sympathetic activation might broaden our understanding of the increased prevalence of coronary artery

\section{KARGER \\ Fax +4161306 1234 \\ E-Mail karger@karger.ch \\ www. karger.com

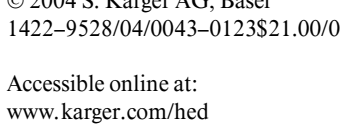

Roland von Känel, MD

Professor of Medicine, Department of General Internal Medicine

University Hospital, CH-3010 Bern (Switzerland)

Tel. +41 3163220 19, Fax +41313821184

E-Mail roland.vonkaenel@insel.ch 
disease (CAD) development and manifestation of acute coronary syndromes with biological and psychosocial states characterized by an activated SNS. This review selectively summarizes work on the relationship between sympathetic nerve activity and hemostasis as well as the molecular mechanisms involved across so many different states like infused adrenergic agents, mental stress and physical exercise. Before delineating the different areas, we provide a brief overview of hemostasis pathways and of the current understanding of hemostatic changes in the pathogenesis of CAD.

\section{Hemostasis Physiology}

Formation and dissolution of a blood clot are physiological processes and the result of a delicate dynamic balance between procoagulant and anticoagulant mechanisms. Activation of hemostasis results in a sequential interaction among a series of proenzymes, enzymes and inhibitors of the coagulation and fibrinolysis cascades. Didactically, we distinguish two closely intertwined coagulation pathways: (1) the intrinsic or contact activation pathway, and (2) the extrinsic or tissue factor (TF) pathway. The intrinsic pathway is triggered upon contact of clotting factor (F) XII with negatively charged surfaces. The extrinsic pathway is initiated by the interaction of TF exposed on vascular cells and endothelial cells upon injury with activated FVII in plasma. In a progressive cascade, both pathways converge to form an activation complex that converts prothrombin to thrombin. Thrombin, in turn, stimulates the conversion of fibrinogen to fibrin the main component of a blood clot. The procoagulant properties of the von Willebrand factor (vWF) derive from its capability to mediate platelet adhesion at sites of endothelial lesions and stabilization of FVIII in plasma. Termination of clot formation involves several anticoagulant mechanisms such as binding of antithrombin III to thrombin, resulting in inactivation of thrombin in a thrombin-antithrombin III complex (TAT).

The fibrinolytic system removes fibrin clots by breaking down cross-linked fibrin chains into soluble fibrin fragments such as $D$-dimer. Fibrinolysis is essentially triggered by tissue-type plasminogen activator (t-PA), which converts fibrin-bound plasminogen to fibrin-cleaving plasmin; t-PA itself is inhibited by type I plasminogen activator inhibitor (PAI-1) - the main physiologic inhibitor of fibrinolysis - in a t-PA-PAI-1 complex. Of note, elevated plasma TAT and $D$-dimer levels are markers of a hypercoagulable state, as they indicate augmented forma- tion of thrombin and fibrin, respectively. In contrast to individual coagulation and fibrinolysis factors, TAT and $D$-dimer are considered activation products of the hemostatic cascade, where $D$-dimer indicates that the entire coagulation and fibrinolysis pathways have been activated [3].

\section{Hypercoagulability and CAD}

Numerous large-scale epidemiological studies suggest that a shift in plasma levels of several hemostasis molecules towards hypercoagulability is associated with CAD $[4,5]$. A hypercoagulable state appears to contribute to both the formation of a coronary thrombus following the rupture of an atherosclerotic plaque [6] and the progression of a plaque due to gradual fibrin accumulation within the vessel wall [7]. The latter is evidenced by studies which detected TF [8], platelet factor 4 [9] and $D$-dimer [10] inside atherosclerotic plaques. For these reasons, procoagulant and antifibrinolytic molecules as well as hypercoagulability markers are increasingly viewed as intermediate end points for an increased risk of a future acute coronary event in both patients with CAD and healthy individuals. These relationships have most consistently been demonstrated with relation to fibrinogen [11], PAI-1 [12] and $D$-dimer [13]. For instance, a recent meta-analysis of prospective studies found that CHD risk is about $70 \%$ greater in those subjects in the top third of the range of $D$-dimer values as compared with those in the bottom third (95\% confidence interval of OR for CAD 1.3-2.2; $\mathrm{p}<0.0001)$ after an average follow-up of 5 years [13]. Despite these reports, there remains uncertainty as to whether hypercoagulability causes CAD or whether it is a consequence of atherosclerosis [14].

Notably, a number of thrombophilic conditions associated with an increased risk of venous thromboembolic disorders are not risk factors for coronary events (e.g. activated protein $\mathrm{C}$ resistance, deficiencies in antithrombin III, protein $\mathrm{S}$ and protein C) [15]. There is increasing evidence that elevated plasma levels of fibrinogen, FVIII clotting activity (FVIII:C) and perhaps $D$-dimer are not only risk factors for CAD but also for venous thrombotic disease $[16,17]$. Nonetheless, the available literature on the effects of the SNS on hemostasis rarely deals with hemostatic risk factors for arterial thrombosis. Therefore, findings and conclusions drawn from the literature reviewed here are not unequivocally transferable to a possible contribution of the SNS to venous thromboembolism. 


\section{Adrenergic Activation}

Remarkably, the notion that adrenergic activation - as mediated by catecholamines - influences hemostatic processes was first reported 100 years ago. A decrease in the whole blood clotting time was observed after injection of epinephrine in humans [18] and in the abdominal cavity of dogs [19]. Similarly, Cannon and Mendenhall [1] found hastened blood coagulation in cats that had been scared by barking dogs. In the search for options to treat hemophilia A several decades ago, it was repeatedly shown that epinephrine infusion increases FVIII:C in plasma from a normal $100 \%$ to an average of $200 \%$ [20]. Aside from this seemingly dose-dependent effect of epinephrine on FVIII:C, we have demonstrated that adrenergic infusions affect blood coagulation, fibrinolysis and platelet activation in a number of ways [20]. In brief, the whole blood clotting time significantly decreases, confirming the historical reports. While epinephrine also appeared to increase FV:C to about $130 \%$ of its normal activity, it had no significant effect on the clotting activity of any other coagulation factor. In addition, epinephrine infusion consistently induced an increase in plasma vWF antigen levels to a mean peak response of $166 \%$. The bulk of studies also suggests that platelets become activated by adrenergic infusion in vivo as evidenced by an increase in different markers (e.g. platelet size, aggregation and releasing factors).

With respect to fibrinolysis, there is convincing evidence demonstrating that epinephrine infusion stimulates the fibrinolytic activity as measured by the euglobulin lysis time; that is, the euglobulin lysis time decreased from a $100 \%$ baseline activity to a mean value of $49 \%$ (range 24-67\%) following epinephrine infusion [20]. A similar picture suggesting a dose-dependent effect emerged for different adrenergic agents (i.e. epinephrine, isoproterenol, phenylephrine) with respect to t-PA. Results with regard to the antifibrinolytic enzyme PAI-1 were inconclusive because epinephrine infusion resulted in increased, decreased or unchanged PAI-1 activity and antigen.

Bearing in mind that most stress hormone infusion studies have not investigated the effects of adrenergic agents on hemostasis at different time points, sympathetic activation, as mimicked by adrenergic infusions, occurred within an approximate time of 15-30 min after termination of the infusion. Even though coagulation and fibrinolysis are both activated to a similar extent (i.e. about twofold) in healthy subjects, hypercoagulability may occur, as evidenced by one study showing increased TAT in re-
Table 1. Hemostatic changes with acute and chronic mental stress $[30,31,72]$

\begin{tabular}{lll}
\hline & Acute stress & Chronic stress \\
\hline Fibrinogen & $\uparrow$ & $\uparrow$ \\
Clotting factor FVII & & $\uparrow$ \\
vWF & $\uparrow$ & \\
t-PA activity & $\uparrow$ & $\downarrow$ \\
PAI-1 & - & $\uparrow$ \\
Platelet activity & $\uparrow$ & \\
TAT & $\uparrow$ & - \\
$D$-dimer & $\uparrow$ & $\uparrow$ \\
\hline
\end{tabular}

$\uparrow=$ Increased; $\downarrow=$ decreased; $-=$ unchanged.

sponse to epinephrine infusion [21]. Study findings with respect to markers of coagulation activation are not straightforward, given that epinephrine infusion elicited no significant changes in TAT, prothrombin fragments 1 +2 , fibrinopeptide $\mathrm{A}$ and fibrinogen/fibrin degradation products in a series of studies [21-23].

Compared to individuals without atherosclerotic diseases, subjects with atherosclerosis appear to experience an even greater and, therefore, potentially harmful shift in the coagulation-fibrinolysis balance toward hypercoagulability following adrenergic infusions [20, 24, 25].

\section{Psychological Stress}

Recent research provides evidence that acute and chronic mental stress are related to the incidence of CAD [26-28], accounting for a substantial proportion of the approximately $50 \%$ of cardiac events not explained by conventional cardiovascular risk factors [29]. Hemostatic mechanisms may reflect a psychobiological pathway linking psychological stress with CAD. More precisely, the literature suggests that increased activities of clotting factors and platelets and/or a reduced fibrinolytic capacity might be one mechanism mediating the adverse impact of psychosocial distress on coronary arteries $[30,31]$.

\section{Acute Mental Stress}

Table 1 contains an overview of altered blood coagulation and fibrinolysis parameters in response to mental stress reaching beyond single study observations. Similarly to the effects of adrenergic infusions on hemostasis, acute stress results in a simultaneous activation of blood coagulation (e.g. fibrinogen, vWF, platelets) and fibrino- 
lysis (t-PA). For instance, Jern et al. [32] found an increase in fibrinogen, vWF antigen, FVII:C and FVIII:C on the one hand and of t-PA antigen and activity on the other hand in healthy individuals following $20 \mathrm{~min}$ of mental stress. Similarly, Kario et al. [33] reported that fibrinogen, vWF antigen, $D$-dimer, plasmin- $\alpha 2$-antiplasmin complex and t-PA antigen had all increased in subjects who had survived a catastrophic stressor. Interestingly, acute mental stress did not significantly affect PAI-1 levels [30]. Notwithstanding this simultaneous activation of coagulation and fibrinolysis pathways, acute stress leads to increases in TAT and $D$-dimer, suggesting both exaggerated thrombin and fibrin formation in healthy individuals [34]. This may have provided an evolutionary benefit to our ancestors, protecting from fatal blood loss when injured in fight or flight. Those who survived then transferred their genes promoting a procoagulant stress response to the next generations.

The situation appears somewhat different in patients suffering from atherosclerotic diseases and related impairment of endothelial anticoagulant function. Here, acute mental stress induces increased activities of coagulation as well as a decrease in fibrinolytic activation [3539]. From a pathogenetic perspective, it is interesting to note that, as opposed to hemodynamic changes (i.e. blood pressure and heart rate), stress-induced hypercoagulability needs more time to recover once the stressor has come to an end. Two studies reported that levels of fibrinogen and $D$-dimer were elevated compared to baseline 45 and 14 min, respectively, after the acute stress situation, while increases in blood pressure and heart rate had both returned to baseline levels [40, 41].

Within minutes, sympathomedullary activation with acute stress releases epinephrine from the adrenal medulla and norepinephrine from sympathetic nerve endings in the bloodstream [42]. Adrenergic infusion and blockade studies in vivo suggest that catecholamines - by stimulating $\beta 2$-adrenergic vascular receptors - provoke a rapid release of FVIII, vWF und t-PA stored in the endothelium into the circulation $[20,24]$. We found that the amount of norepinephrine secretion and the sensitivity of the $\beta 2$ adrenergic receptor together explained almost $60 \%$ of the variance in thrombin formation with acute mental stress [34]. Epinephrine and norepinephrine also activate platelets in vivo via $\alpha 2$-adrenergic receptors [20]. The precise mechanisms by which the SNS regulates the hepatic clearance of fibrinolysis molecules is not yet fully understood $[20,24]$. Notably, the unique stimulation of $\beta 2$-adrenergic receptors does not result in fibrin formation; clearly, the a2-adrenergic stimulation of platelets is also required
[24]. Experimental studies suggest that nonselective $\beta$ adrenoreceptor-blocking drugs abolish the stress-induced increase in FVIII:C and vWF antigen but also fibrinolysis in vivo [20, 24].

\section{Chronic Mental Stress}

In contrast to acute mental stress, chronic mental stress results in a reduced fibrinolytic capacity as evidenced by a dwindling of t-PA activity and an increase of PAI-1 [30]. As seen with acute stress, an increase in plasma fibrinogen levels [30] and $D$-dimer [31], but also in FVII [30] has been found, resulting in net hypercoagulability (table 1). There is much evidence that low socioeconomic status and the struggle to cope with the social burden of a low income or poor education are inversely related to plasma fibrinogen and FVII levels [30]. Similarly, fibrinogen was higher in subjects who perceived job stress than in those without it in a number of studies [30]. Unlike socioeconomic status, the relation between a hypercoagulable state and job strain is independent of health behavior [30]. Furthermore, impaired fibrinolysis (decrease in t-PA activity) has been related to high job demands [43]. Overcommitment to work, defining a personal coping style characterized by an incapability to disengage oneself from work obligations, has also been associated with impaired fibrinolysis (i.e. decrease in t-PA activity and increase in PAI-1 activity) [44].

Significant increases in $D$-dimer have been found in chronically distressed spousal caregivers of Alzheimer patients as compared to age- and gender-matched non-caregiving controls [45]. Additionally, we found an association between the number of negative life events within the previous 4 weeks and plasma $D$-dimer levels in a sample of caregivers of community-dwelling Alzheimer patients [46]. Caregivers who reported relatively more chronic life stress above and beyond that experienced by providing care to their demented spouse also had a higher acute stress procoagulant activity [47]. Of note, relationships between $D$-dimer and stress in the caregivers were independent of medication use and established cardiovascular risk factors. Remarkably, chronic stress appears not to affect plasma TAT levels $[42,48]$. This may be connected to the short half-life of TAT of several minutes, which may render this coagulation activation marker less detectable in plasma than $D$-dimer, which has a half-life of up to $48 \mathrm{~h}$ [31].

Chronic stress can lead to a state of 'vital exhaustion' that has been shown to predict cardiovascular disease events [49-51]. Several studies have found that subjects who are exhausted have an impaired fibrinolytic capacity 
as evidenced by an increase in PAI-1 [52-55]. As recently shown by our group, exhausted subjects who were homozygous for the $5 \mathrm{G}$ allele of the PAI-1 $4 \mathrm{G} / 5 \mathrm{G}$ gene polymorphism had higher plasma PAI-1 antigen levels than nonexhausted subjects who were homozygous for the $5 \mathrm{G}$ allele. Subjects carrying the $4 \mathrm{G}$ allele (either $4 \mathrm{G} / 4 \mathrm{G}$ or $4 \mathrm{G} / 5 \mathrm{G})$ did not differ in their PAI-1 levels as related to the severity of exhaustion [55].

The molecular mechanisms underlying hemostatic changes with chronic stress are only emerging. Chronic stress may underlie stimulation of vascular $\beta 1$-adrenergic receptors and a subsequent decrease in t-PA release from the endothelium [30]. Downregulation of $\beta 2$-adrenergic receptors might also be a mechanism resulting in less t-PA release at times of superimposed short-term sympathetic activation [30]. Less circulating t-PA would then be available to inhibit PAI-1. In line with the observed decrease in fibrinolytic activity with chronic stress, restraint stress [56] and isoproterenol injection [57] have both been shown to result in upregulation of PAI-1 mRNA in animal models. In addition, sustained overactivity of the SNS, as monitored by overnight urine catecholamine excretion, was associated with a procoagulant profile in the morning in male factory workers [58]. Overnight sympathetic activity and accompanying catecholamine spillover due to repeated hypoxic bursts and arousals during sleep have also been implicated in procoagulant changes observed in patients suffering from obstructive sleep apnea [59]. For instance, previous studies in patients with sleep apnea found an independent relationship between plasma epinephrine and platelet aggregability [60] and between average minimal oxygen desaturation during sleep and plasma fibrinogen [61].

\section{Physical Exercise}

Regular physical exercise is generally considered to have favorable effects on health outcomes, particularly in reducing the risk of cardiac diseases. However, several studies have demonstrated strenuous exercise to be involved in the pathogenesis of sudden death $[62,63]$. The underlying mechanisms through which exercise may promote cardiovascular harm include plaque rupture that can evoke coronary spasm, thrombosis or both [64]. A procoagulant state as elicited by sympathetic activation with physical activity might accelerate coronary thrombus formation following plaque rupture [20]. Of note, thrombotic occlusion of a coronary artery is a rare cause of sudden cardiac death in young athletes [65]. On the other hand, coronary thrombosis becomes increasingly important as a cause of sudden cardiac death in individuals beyond the age of 35 as the prevalence of coronary atherosclerosis increases [66].

The effects of exercise on hemostasis have been recently reviewed and discussed $[67,68]$. Physical exercise concomitantly activates blood coagulation and enhances fibrinolysis in a similar way to that seen with adrenergic infusions and acute mental stress. For instance, vWF, fibrinolytic activity and $D$-dimer were all higher in marathon runners $4 \mathrm{~h}$ after a race as compared to values before the race [69]. Interestingly, $\mathrm{vWF}$ and $D$-dimer, but not fibrinolytic activity, were still elevated the morning after the race, suggesting sustained hypercoagulability. Pooled data reveal that the activated partial thromboplastin time, indicating the activity of the intrinsic pathway of blood coagulation, is shortened by $7-38 \%$ after exercise [67]. Several studies have assessed whether or not exercise induces changes in individual components of the coagulation pathways, demonstrating a consistent increase in FVIII:C by $200-400 \%$. The increase in FVIII is directly related to exercise intensity and an individual's training status. Whether or not exercise is accompanied by changes in plasma fibrinogen is controversial, with studies showing increased, decreased and unchanged plasma fibrinogen levels after exercise.

Previous studies have consistently demonstrated that fibrinolytic activity is significantly enhanced after exercise. The rise in blood fibrinolysis is mainly due to an increase in t-PA activity and a decrease in PAI-1. This increase in blood fibrinolysis after exercise depends on exercise intensity, its duration and the training condition of a person. Several studies have also demonstrated that strenuous exercise results in a significant increase in platelet count, probably mediated by an acute release of platelets from the spleen, bone marrow and lungs. The shortterm effects of exercise on platelet function are somewhat controversial. In sum, short-term exercise activates blood coagulation and enhances blood fibrinolysis. In healthy individuals, the delicate balance between clot formation and clot dissolution appears to be maintained. Of note, regular physical exercise diminishes procoagulant activation with acute physical exercise. Such a protective effect of regular exercise is in line with the observation that welltrained people have a several-fold decreased risk of experiencing sudden death during exercise as compared to the untrained. 


\section{Limitations}

Notwithstanding the evidence that the SNS modulates hemostasis and that coagulation activation outweighs fibrinolysis activation in healthy individuals and to an even greater extent in certain high-risk individuals, we do not know whether these hemostatic changes have any clinical implications. More precisely, the literature lacks data on a prospective relationship between procoagulant activity related to both mental stress and physical exercise and heightened coronary risk. In the case of such an adverse effect, specific target interventions would seem warranted. At present, there are only few data suggesting that adrenergic receptor-blocking drugs [20,24] or regular physical exercise [70] may attenuate acute procoagulant changes with SNS activation. Moreover, whether a stress inoculation program diminishes exaggerated procoagulant changes in response to short-term mental arousal is unknown. There is, however, a parallel line of research suggesting that improving stress management skills by cognitive behavioral therapy may reduce physiological responses to acute mental stress [71].

\section{Comment}

Adrenergic infusions, mental stress and physical exercise are conditions in which activation of the SNS is profound enough to elicit significant changes in hemostatic function. It comes as no surprise that all three models of SNS activation outlined in this review are characterized by similar changes in the blood coagulation and fibrinolysis pathways. An accumulating body of literature suggests that catecholamines and adrenergic receptor functioning may mediate these changes. Further research is warranted to further delineate the precise molecular mechanisms involved.

Apparently, acute activation of the SNS results in an increase in both coagulant (i.e. fibrinogen, FVIII, vWF, platelet activity) and fibrinolytic (t-PA) activity. Charles Darwin's evolutionary paradigm of 'the survival of the fittest' in a fight-flight situation, as it was termed by Walter Cannon, provides an explanation for why even healthy individuals experience exaggerated clotting at times of acute SNS activation. At present, we do not know whether this physiological hypercoagulability plays a significant role in the initiation and progression of atherosclerosis over the course of an individual's life span. However, there is some evidence to suggest that hypercoagulability as elicited by the SNS might induce cardiovascular harm in individuals with preexisting atherosclerosis, in persons subjected to chronically stressful life circumstances and in the physically untrained. Clearly, this hypothesis needs to be tested in prospectively designed studies.

\section{References}

1 Cannon WB, Mendenhall WL: Factors affecting the coagulation time of blood. IV. The hastening of coagulation in pain and emotional excitement. Am J Physiol 1914;34:251-261.

$\checkmark 2$ Folsom AR: 'New' risk factors for atherosclerotic diseases. Exp Gerontol 1999;34:483-490.

3 Colman RW, Clowes AW, George JN, Hirsh J, Marder VJ (eds): Hemostasis and Thrombosis. Basic Principles and Clinical Practice. Philadelphia, Williams \& Wilkins, 2001.

4 Koenig W: Haemostatic risk factors for cardiovascular diseases. Eur Heart J 1998;19(suppl C):C39-C43.

$\checkmark 5$ Folsom AR: Hemostatic risk factors for atherothrombotic disease: An epidemiologic view. Thromb Haemost 2001;86:366-373.

$\checkmark 6$ Ruberg FL, Loscalzo J: Prothrombotic determinants of coronary atherothrombosis. Vasc Med 2002;7:289-299.

$>7$ Falk E, Fernandez-Ortiz A: Role of thrombosis in atherosclerosis and its complications. Am J Cardiol 1995;75:3B-11B.
8 Moreno PR, Bernardi VH, Lopez-Cuellar J, Murcia AM, Palacios IF, Gold HK, Mehran R, Sharma SK, Nemerson Y, Fuster V, Fallon JT: Macrophages, smooth muscle cells, and tissue factor in unstable angina. Implications for cellmediated thrombogenicity in acute coronary syndromes. Circulation 1994;94:3090-3097.

9 Pitsilos S, Hunt J, Mohler ER, Prabhakar AM, Poncz M, Dawicki J, Khalapyan TZ, Wolfe ML, Fairman R, Mitchell M, Carpenter J, Golden MA, Cines DB, Sachais BS: Platelet factor 4 localization in carotid atherosclerotic plaques: Correlation with clinical parameters. Thromb Haemost 2003;90:1112-1120.

10 Smith EB, Keen GA, Grant A, Stirk C: Fate of fibrinogen in human arterial intima. Arteriosclerosis 1990;10:263-275.

$>11$ Koenig W: Fibrin(ogen) in cardiovascular disease: An update. Thromb Haemost 2003;89: 601-609.
12 Kohler HP, Grant PJ: Plasminogen-activator inhibitor type 1 and coronary artery disease. $\mathrm{N}$ Engl J Med 2000;342:1792-1801.

13 Danesh J, Whincup P, Walker M, Lennon L, Thomsom A, Appleby P, Rumley A, Lowe G: Fibrin D-dimer and coronary heart disease: Prospective study and meta-analysis. Circulation 2001;103:2323-2327.

14 Haverkate F: Levels of haemostatic factors, arteriosclerosis and cardiovascular disease. Vascul Pharmacol 2002;39:109-112.

15 Thomas DP, Roberts HR: Hypercoagulability in venous and arterial thrombosis. Ann Intern Med 1997;126:638-644.

16 Tripodi A: Levels of coagulation factors and venous thromboembolism. Haematologica 2003;88:705-711.

17 Cushman M, Folsom AR, Wang L, Aleksic N Rosamond WD, Tracy RP, Heckbert SR: Fibrin fragment D-dimer and the risk of future venous thrombosis. Blood 2003;101:12431248 . 
18 von den Velden R: Zur kreislaufanaleptischen und telehämostyptischen Wirkung des Nebennierenextraktes. Münch Med Wochenschr 1911;58:184-188.

19 Vosburgh CH, Richards AN: An experimental study of the sugar content and extra vascular coagulation of the blood after administration of adrenalin. Am J Physiol 1903;9:35-51.

20 von Känel R, Dimsdale JE: Effects of sympathetic activation by adrenergic infusions on hemostasis in vivo. Eur $\mathrm{J}$ Haematol 2000;65: 357-369.

-21 Wallen NH, Goodall AH, Li N, Hjemdahl P: Activation of haemostasis by exercise, mental stress and adrenaline: Effects on platelet sensitivity to thrombin and thrombin generation. Clin Sci (Lond) 1999;97:27-35.

-22 van der Poll T, Levi M, Dentener M, Jansen PM, Coyle SM, Braxton CC, Buurman WA, Hack CE, ten Cate JW, Lowry SF: Epinephrine exerts anticoagulant effects during human endotoxemia. J Exp Med 1997;185:1143-1148.

-23 Mannucci PM, Aberg M, Nilsson IM, Robertson B: Mechanism of plasminogen activator and factor VIII increase after vasoactive drugs. Br J Haematol 1975;30:81-93.

-24 von Känel R, Dimsdale JE, Adler KA, Dillon E, Perez CJ, Mills PJ: Effects of nonspecific beta-adrenergic stimulation and blockade on blood coagulation in hypertension. J Appl Physiol 2003;94:1455-1459.

$\checkmark 25$ Lande K, Kjeldsen SE, Os I, Westheim A, Hjermann I, Eide I, Gjesdal K: Increased platelet and vascular smooth muscle reactivity to lowdose adrenaline infusion in mild essential hypertension. J Hypertens 1988;6:219-225.

-26 Hemingway H, Marmot M: Evidence based cardiology: Psychosocial factors in the aetiology and prognosis of coronary heart disease. Systematic review of prospective cohort studies BMJ 1999;318:1460-1467.

-27 Rozanski A, Blumenthal JA, Kaplan J: Impact of psychological factors on the pathogenesis of cardiovascular disease and implications for therapy. Circulation 1999;99:2192-2217.

-28 Krantz DS, McCeney MK: Effects of psychological and social factors on organic disease: A critical assessment of research on coronary heart disease. Annu Rev Psychol 2002;53:341369.

-29 Black PH, Garbutt LD: Stress, inflammation and cardiovascular disease. J Psychosom Res 2002;52:1-23.

-30 von Känel R, Mills PJ, Fainman C, Dimsdale JE: Effects of psychological stress and psychiatric disorders on blood coagulation and fibrinolysis: A biobehavioral pathway to coronary artery disease? Psychosom Med 2001;63:531544.

-31 von Känel R, Dimsdale JE: Fibrin D-dimer: A marker of psychosocial distress and its implications for research in stress-related coronary artery disease. Clin Cardiol 2003;26:164-168.

- 32 Jern C, Eriksson E, Tengborn L, Risberg B, Wadenvik H, Jern S: Changes of plasma coagulation and fibrinolysis in response to mental stress. Thromb Haemost 1989;62:767-771.
33 Kario K, Matsuo T, Kobayashi H, Yamamoto K, Shimada K: Earthquake-induced potentiation of acute risk factors in hypertensive elderly patients: Possible triggering of cardiovascular events after a major earthquake. J Am Coll Cardiol 1997;29:926-933.

34 von Känel R, Mills PJ, Ziegler MG, Dimsdale JE: Effect of beta2-adrenergic receptor functioning and increased norepinephrine on the hypercoagulable state with mental stress. Am Heart J 2002;144:68-72.

35 Tomoda F, Takata M, Kagitani S, Kinuno H, Yasumoto K, Tomita S, Inoue H: Different platelet aggregability during mental stress in two stages of essential hypertension. Am J Hypertens 1999;12:1063-1070.

36 Palermo A, Bertalero P, Pizza N, Amelotti R, Libretti A: Decreased fibrinolytic response to adrenergic stimulation in hypertensive patients. J Hypertens Suppl 1989;7:S162-S163.

37 Grignani G, Pacchiarini L, Zucchella M, Tacconi F, Canevari A, Soffiantino F, Tavazzi L: Effect of mental stress on platelet function in normal subjects and in patients with coronary artery disease. Haemostasis 1992;22:138-146.

38 Canevari A, Tacconi F, Zucchella M, Pacchiarini L, Soffiantino F, Grignani G: Antithrombin III biological activity and emotional stress in patients with coronary artery disease. Haematologica 1992;77:180-182.

39 von Känel R, Dimsdale JE, Ziegler MG, Mills PJ, Patterson TL, Lee SK, Grant I: Effect of acute psychological stress on the hypercoagulable state in subjects (spousal caregivers of patients with Alzheimer's disease) with coronary or cerebrovascular disease and/or systemic hypertension. Am J Cardiol 2001;87:1405-1408.

40 Steptoe A, Kunz-Ebrecht S, Owen N, Feldmann PJ, Rumley A, Lowe GD, Marmot M: Influence of socioeconomic status and job control on plasma fibrinogen responses to acute mental stress. Psychosom Med 2003;65:137144.

41 von Känel R, Dimsdale JE, Adler KA, Patterson TL, Mills PJ, Grant I: Effects of depressive symptoms and anxiety on hemostatic responses to acute mental stress and recovery in the elderly. Psychiatry Res, in press.

42 Dimsdale JE, Ziegler MC: What do plasma and urinary measures of catecholamines tell us about human response to stressors? Circulation 1991;83(4 suppl):II36-II42.

43 Ishizaki M, Tsuritani I, Noborisaka Y, Yamada Y, Tabata M, Nakagawa H: Relationship between job stress and plasma fibrinolytic activity in male Japanese workers. Int Arch Occup Environ Health 1996;68:315-320.

44 Vrijkotte TG, van Doornen LJ, Geus EJ: Work stress and metabolic and hemostatic risk factors. Psychosom Med 1999;61:796-805.

45 von Känel R, Dimsdale JE, Adler KA, Patterson TL, Mills PJ, Grant I: Exaggerated plasma fibrin turnover (D-dimer) in Alzheimer caregivers as compared to non-caregiving controls. Gerontology, in press.
46 von Känel R, Dimsdale JE, Patterson TL, Grant I: Association of negative life event stress with coagulation activity in elderly Alzheimer caregivers. Psychosom Med 2003;65: $145-150$.

47 von Känel R, Dimsdale JE, Patterson TL, Grant I: Acute procoagulant stress response as a dynamic measure of allostatic load in Alzheimer caregivers. Ann Behav Med 2003;26: 42-48.

48 von Känel R, Bardwell WA, Berry CC, Dimsdale JE: Independent contribution of psychological factors to fibrin turnover in subjects with sleep apnoea and/or systemic hypertension. Clin Sci (Lond) 2002;103:331-337.

49 Cole SR, Kawachi I, Sesso HD, Paffenbarger RS, Lee IM: Sense of exhaustion and coronary heart disease among college alumni. Am J Cardiol 1999;84:1401-1405.

50 Appels A, Mulder P: Excess fatigue as a precursor of myocardial infarction. Eur Heart J 1988; 9:758-764.

51 Kop WJ, Appels AP, Mendes de Leon CF, de Swart HB, Bar FW: Vital exhaustion predicts new cardiac events after successful coronary angioplasty. Psychosom Med 1994;56:281287.

52 Raikkonen K, Lassila R, Keltikangas-Jarvinen L, Hautanen A: Association of chronic stress with plasminogen activator inhibitor-1 in healthy middle-aged men. Arterioscler Thromb Vasc Biol 1996;16:363-367.

53 Kop WJ, Hamulyak K, Pernot C, Appels A: Relationship of blood coagulation and fibrinolysis to vital exhaustion. Psychosom Med 1998; 60:352-358.

54 van Diest R, Hamulyak K, Kop WJ, van Zandvoort C, Appels A: Diurnal variations in coagulation and fibrinolysis in vital exhaustion. Psychosom Med 2002;64:787-792.

55 von Känel R, Maly FE, Frey K, Fischer JE: Contribution of the type 1 plasminogen activator inhibitor $4 \mathrm{G} / 5 \mathrm{G}$ gene polymorphism to impaired fibrinolysis in vital exhaustion. Ital Heart J 2003;4:791-796.

56 Yamamoto K, Takeshita K, Shimokawa T, Yi $\mathrm{H}$, Isobe K, Loskutoff DJ, Saito H: Plasminogen activator inhibitor-1 is a major stress regulated gene: Implications for stress induced thrombosis in aged individuals. Proc Natl Acad Sci USA 2002;99:890-895.

57 Venugopal B, Sharon R, Abramovitz R, Khasin A, Miskin R: Plasminogen activator inhibitor-1 in cardiovascular cells: Rapid induction after injecting mice with kainate or adrenergic agents. Cardiovasc Res 2001;49:476-483.

58 von Känel R, Kudielka BM, Abd-El-Razik A, Gander M, Frey K, Fischer JE: Relationship between overnight neuroendocrine activity and morning hemostasis in working men. Clin Sci (Lond), in press.

59 von Känel R, Dimsdale JE: Hemostatic alterations in patients with obstructive sleep apnea and the implications for cardiovascular disease. Chest 2003;124:1956-1967. 
60 Eisensehr I, Ehrenberg BL, Noachtar S, Korbett K, Byrne A, McAuley A, Palabrica T: Platelet activation, epinephrine, and blood pressure in obstructive sleep apnea syndrome. Neurology 1998;51:188-195.

61 Wessendorf TE, Thilmann AF, Wang YM, Schreiber A, Konietzko N, Teschler H: Fibrinogen levels and obstructive sleep apnea in ischemic stroke. Am J Respir Crit Care Med 2000; 162:2039-2042.

62 Maron BJ, Poliac LC, Roberts WO: Risk for sudden cardiac death associated with marathon running. J Am Coll Cardiol 1996;28:428431.

63 Albert CM, Mittleman MA, Chae CU, Lee IM, Hennekens $\mathrm{CH}$, Manson JE: Triggering of sudden death from cardiac causes by vigorous exertion. N Engl J Med 2000;343:1355-1361.
64 Ciampricotti R, el Gamal MI, Bonnier JJ, Relik TH: Myocardial infarction and sudden death after sport: Acute coronary angiographic findings. Cathet Cardiovasc Diagn 1989;17: 193-197.

65 Maron BJ: Sudden death in young athletes. N Engl J Med 2003;349:1064-1075.

66 Virmani R, Burke AP, Farb A: Sudden cardiac death. Cardiovasc Pathol 2001;10:211-218.

67 Smith JE: Effects of strenuous exercise on haemostasis. Br J Sports Med 2003;37:433-435.

68 el-Sayed MS: Effects of exercise on blood coagulation, fibrinolysis and platelet aggregation. Sports Med 1996;22:282-298.
69 Siegel AJ, Stec JJ, Lipinska I, Van Cott EM, Lewandrowski KB, Ridker PM, Tofler GH: Effect of marathon running on inflammatory and hemostatic markers. Am J Cardiol 2001; 88:918-920.

70 Smith DT, Hoetzer GL, Greiner JJ, Stauffer BL, DeSouza CA: Effects of ageing and regular aerobic exercise on endothelial fibrinolytic capacity in humans. J Physiol 2003;546:289_ 298.

71 Gaab J, Blattler N, Menzi T, Pabst B, Stoyer S,

Ehlert U: Randomized controlled evaluation of the effects of cognitive-behavioral stress management on cortisol responses to acute stress in healthy subjects. Psychoneuroendocrinology 2003;28:767-779.

72 Camacho A, Dimsdale JE: Platelets and psychiatry: Lessons learned from old and new studies. Psychosom Med 2000;62:326-336. 